\title{
Significance of tests of iron nutrition in pregnancy ${ }^{1}$
}

\author{
J. METZ, L. TURCHETTI, B. COMBRINK, AND S. KRAWITZ \\ From the Department of Haematology, South African Institute for Medical Research, \\ and Bridgman Memorial Hospital, Johannesburg
}

SYNOPSIS Tests of iron and folate nutrition have been carried out in early pregnancy and at delivery in 63 Bantu females. Accepted normal values for serum iron, and percentage saturation of transferrin, but not for unsaturated iron-binding capacity, for non-pregnant subjects were found to apply equally well in pregnancy. Concomitant folate deficiency in early pregnancy did not render tests of iron deficiency less valid. The unsaturated iron-binding capacity, percentage saturation, and marrow iron stores in early pregnancy all showed a significant correlation with the haemoglobin value at term. Patients with normal marrow iron stores and a percentage saturation of transferrin of 20 or more at or before the 24th week are unlikely to become anaemic from iron deficiency during pregnancy.

Iron-deficiency anaemia occurs commonly in pregnancy, and is of major diagnostic and therapeutic importance. Ideally, iron deficiency should be diagnosed before the development of severe anaemia, and to this end, a number of special tests of iron nutrition are available. The present study was undertaken to determine (1) the relationship of the serum iron concentration, unsaturated iron-binding capacity, percentage saturation of transferrin, and mean corpuscular haemoglobin concentration to the bone marrow iron stores in early pregnancy and at delivery; (2) the effect of folate deficiency on tests of iron nutrition in pregnancy; (3) the value of tests for iron deficiency in early pregnancy in predicting the incidence of anaemia in late pregnancy.

\section{PROCEDURE}

SUBJECTS STUDIED Sixty-three Bantu women attending the ante-natal clinic at the Bridgman Memorial Hospital, Johannesburg (altitude 5,740 ft.), were studied. Consecutive patients with haemoglobin values less than $12.5 \mathrm{~g} . \%$, and in whom the duration of pregnancy, as calculated from the last menstrual period and the size of the uterus, was 24 weeks or less, were studied as outlined below. The haemoglobin and haematocrit values in healthy subjects resident at the Johannesburg altitude are significantly higher than at sea level, and in healthy adult females, the mean haemoglobin value is $14.0 \mathrm{~g}$. \%. When first seen, 10 patients were 12 to 16 weeks pregnant, 33 were 17 to 20 weeks, and 20 were 21 to 24 weeks.

FIRST VISIT On the first morning of study, a dose of $10 \mathrm{~g}$. of 1-histidine monohydrochloride was administered

'This work was supported by a research grant from the World Health Organization.

Received for publication 7 September 1965. orally in approximately $100 \mathrm{ml}$. of water, and all urine passed over the ensuing six hours collected. Venous blood was drawn for estimation of haemoglobin, haematocrit, serum iron, unsaturated iron-binding capacity, and serum Lactobacillus casei folate activity, and blood films were prepared. Blood specimens for the haematological investigations were mixed with dried sequestrene, while those for folic acid assays were placed in sterile containers and allowed to clot. Blood for serum iron and unsaturated iron-binding capacity estimations was allowed to drip directly from the needle into an iron-free container. A specimen of bone marrow was aspirated from the sternum. After collecting these specimens, the rate of removal of an intravenously injected test dose of folic acid (15 $\mu \mathrm{g} . / \mathrm{kg}$. body weight) from the blood was studied by the method described by Chanarin, MacGibbon, O’Sullivan, and Mollin (1959). Blood for folic acid assay was drawn from another vein exactly 15 minutes after the injection. Patients were instructed to return after one week.

SECOND VISIT By the time patients returned one week later, the blood and bone marrow samples had been examined. Seventeen patients were either not anaemic or showed mild anaemia only, without morphological evidence of iron or folate deficiency, and these subjects received no treatment during pregnancy. The other 46 patients showed morphological evidence of iron deficiency in the peripheral blood, together with diminished or absent marrow iron stores, and these patients received iron therapy. Of these 46 patients with iron deficiency, 17 showed megaloblasts and/or giant myeloid cells in the marrow, and they received folic acid as well as iron therapy during pregnancy.

SUBSEQUENT VISITS On each subsequent visit, blood was drawn for haemoglobin and haematocrit estimation. Delivery took place in hospital, and patients were restudied two to four days after delivery, when all investiga- 
tions, including blood count, bone marrow, serum $L$. casei folate activity, folic acid clearance test, and urinary formiminoglutamic acid (Figlu) test were repeated. The period of two to four days was allowed to elapse as some patients had taken tablets on the day before delivery.

\section{METHODS}

Haemoglobin was estimated as cyanmethaemoglobin using a commercially available standard. The haematocrit was measured in an International microhaematocrit centrifuge. Blood and marrow films were stained with Wright's stain. The marrow films were examined for megaloblasts and giant myeloid cells. Marrow films were also stained for haemosiderin, and iron stores graded from 0 to +6 (Rath and Finch, 1948). At least 10 good-size marrow particles were examined from each aspirate. In normal subjects the iron stores are +2 to +3 .

Serum iron and unsaturated iron-binding capacity measurements were carried out by Dr. T. H. Bothwell by a modification of the method of Bothwell and Mallett (1955). Serum folate activity was assayed with $L$. casei by the methods of Herbert (1961) and of Waters and Mollin (1961), and the 15-minute folic acid level with Streptococcus faecalis according to Toepfer, Zook, Orr, and Richardson (1951). The urine samples collected after histidine loading were assayed for Figlu by the method of Chanarin and Bennett (1962). Normal values for these various tests are as follows: serum iron 70 to $150 \mu \mathrm{g} . \%$; unsaturated iron-binding capacity 250 to $400 \mu \mathrm{g} . \%$; percentage saturation 25 to 50 ; serum $L$. casei folate 5 to
$15 \mu \mathrm{mg} . / \mathrm{ml}$.; 15-minute $S$. faecalis folic acid 21 to $\frac{\stackrel{0}{\vec{g}^{3}}}{3}$ $\mu \mathrm{mg}$./ml.; urinary Figlu 0 to $6 \mathrm{mg}$. in six hours.

The blood and marrow films were examined indepe $\overrightarrow{\mathrm{g}} \mathrm{d}-$ ently by two of the authors (L.T. and J.M.) without any knowledge of the ancillary findings.

\section{RESULTS}

DIAGNOSTIC CRITERIA FOR BODY IRON DEFICIENCY IN PREGNANCY The results of some tests of iron nuffition related to marrow iron stores in early pregnarey and at delivery are shown in Figure I. In all patients with adequate iron stores $(+2$ or more), the serwim iron value was greater than $75 \mu \mathrm{g} . \%$, the percent不 saturation of transferrin greater than 20 , and the mean corpuscular haemoglobin concentration (M.C.H.C.) $31 \%$ or greater. Values for unsaturatee d iron-binding capacity of greater than $300 \mu \mathrm{g} . \%$ wete noted in some patients despite adequate marrow iron stores. The serum iron, unsaturated iron-binding capacity, and percentage saturation were sometimes normal in patients without stainable iron in the bohe marrow. On the other hand, the serum iron and percentage saturation were sometimes subnormation patients with significant, although subnorm 1 , amounts of stainable iron in the bone marrow.

EFFECT OF FOLATE DEFICIENCY ON TESTS OF IR S N NUTRITION In megaloblastic anaemia due to folête

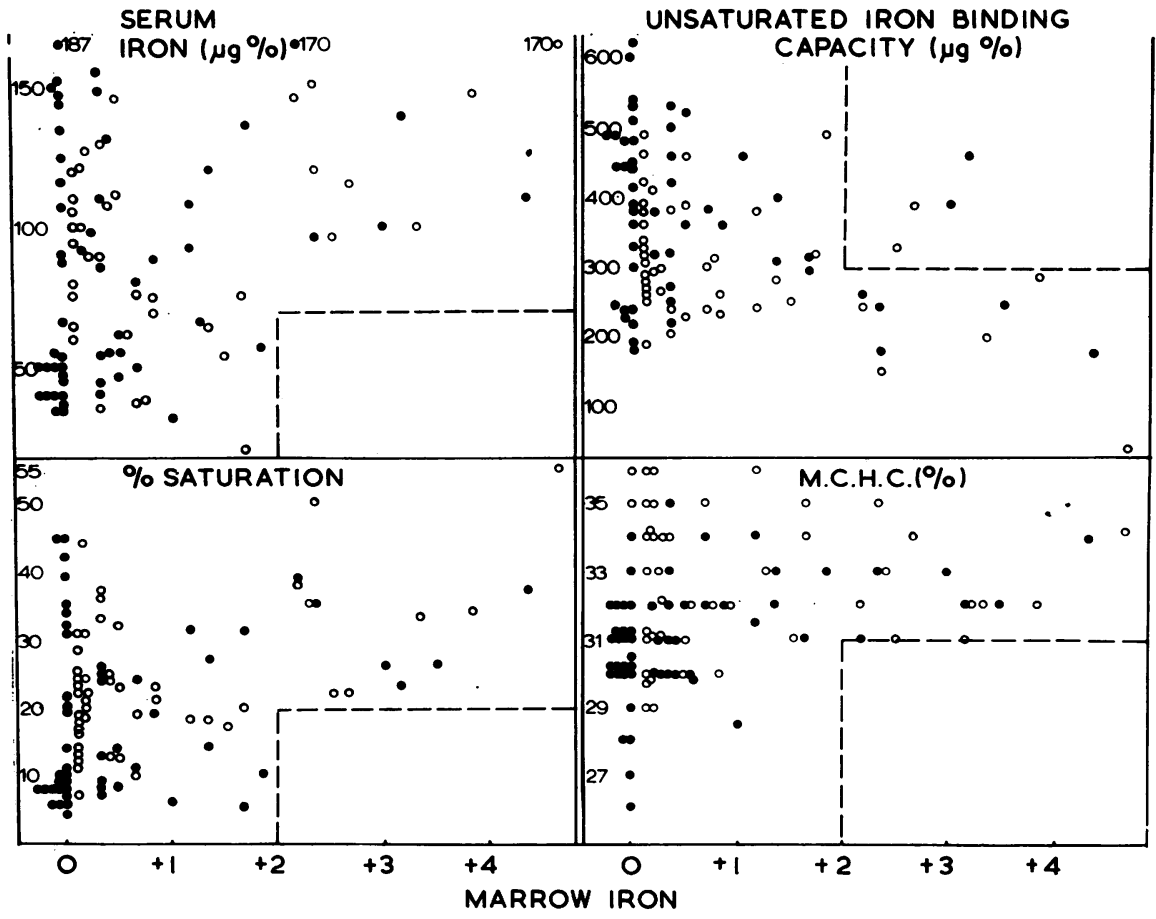

FIG. 1. Tests of iron nutrition in pregnancy correlated with the bone marrow iron stores. The dotted lines indicate the 3 lower limit of normal, except with the unsaturated iron-binding 음 capacity where theo horizontal dotted line represents tho upper limit of normal. Closed circles $=$ early pregnancy. Open circles $=a t$ delivery. 
TABLE I

EFFECT OF CONCOMITANT FOLATE DEFICIENCY ON MEAN VALUES FOR TESTS OF IRON NUTRITION IN PREGNANT PATIENTS WITH DIMINISHED IRON STORES

Serum Iron $(\mu g . \%)$

Unsaturated Iron-

Transferrin

Saturation (\%)

Marrow Iron

( $\mu \mathrm{g} . \%)$

\begin{tabular}{|c|c|c|c|c|c|}
\hline Bone marrow & $\begin{array}{l}\text { Megaloblastic } \\
\text { Normoblastic }\end{array}$ & $\begin{array}{l}82 \cdot 1 \\
83 \cdot 8\end{array}$ & $\begin{array}{l}376 \cdot 2 \\
376 \cdot 5\end{array}$ & $\begin{array}{l}18 \cdot 7 \\
19 \cdot 0\end{array}$ & $\begin{array}{l}\mathbf{0} \\
\mathbf{0}\end{array}$ \\
\hline $\begin{array}{l}\text { Serum L. casei folate } \\
(\mathrm{m} \mu \mathrm{g} . / \mathrm{ml} .)\end{array}$ & $\begin{array}{l}<3.0 \\
>3.0\end{array}$ & $\begin{array}{l}82 \cdot 7 \\
83 \cdot 4\end{array}$ & $\begin{array}{l}409 \cdot 1 \\
365 \cdot 8\end{array}$ & $\begin{array}{l}16 \cdot 7 \\
20 \cdot 1\end{array}$ & $\begin{array}{l}\mathbf{0} \\
\mathbf{0}\end{array}$ \\
\hline
\end{tabular}

${ }^{1}$ The differences are not statistically significant

deficiency, the serum iron level may be elevated, and the percentage saturation of transferrin and marrow iron stores increased. Thus these tests might be expected to be less sensitive indices of iron nutrition when there is associated folate deficiency. To test this the result of tests of iron nutrition in patients with diminished iron stores and either megaloblasts and/or giant myeloid cells in the marrow were compared with those in whom the marrow was entirely normoblastic. No difference was apparent (Table I). Similarly, when the results of tests of iron nutrition in patients with serum $L$. casei folate levels of less than $3.0 \mu \mathrm{mg} . / \mathrm{ml}$. were compared with those where the level was greater than $3.0 \mu \mathrm{mg}$. $/ \mathrm{ml}$. no obvious difference was apparent.

TESTS OF IRON NUTRITION IN EARLY PREGNANCY AND THE SUBSEQUENT DEVELOPMENT OF ANAEMIA To test their validity as prediction parameters of the subsequent development of anaemia, the values for marrow iron, serum iron, unsaturated iron-binding capacity, percentage saturation of transferrin, and M.C.H.C. in early pregnancy were plotted against the haemoglobin value in the third trimester, in patients who received no iron therapy during pregnancy. The unsaturated iron-binding capacity, percentage saturation, and marrow iron all showed a significant correlation with the haemoglobin value in the third trimester, the percentage saturation showing the best fit (Fig. 2).

\section{DISCUSSION}

While hypochromic anaemia (with diminished iron stores) is an absolute diagnostic criterion of iron

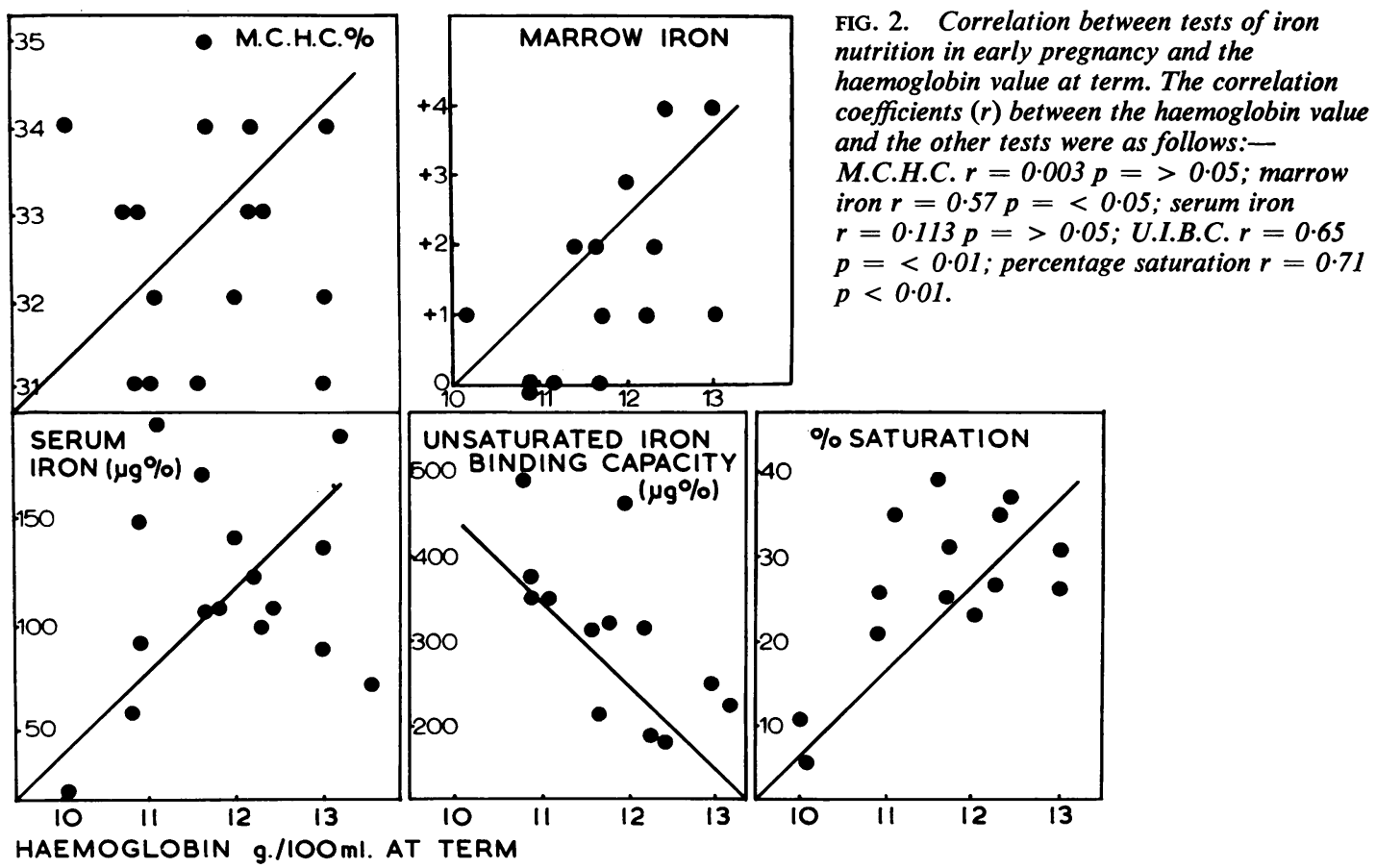

FIG. 2. Correlation between tests of iron nutrition in early pregnancy and the haemoglobin value at term. The correlation coefficients $(r)$ between the haemoglobin value the other tests were as follows:iron $r=0.57 p=<0.05$; serum iron $r=0.113 p=>0.05 ;$ U.I.B.C. $r=0.65$ $p=<0.01$; percentage saturation $r=0.71$ $p<0.01$. 
deficiency in pregnancy, the aim of this study was to evaluate diagnostic indices before the development of anaemia. As the major portion of the maternal iron requirements during pregnancy occur from approximately the middle of the second trimester until delivery (Bothwell and Finch, 1962), it is not unreasonable to regard absence of stainable iron in the marrow in early pregnancy as an absolute index of body iron deficiency. Thus, in the present study, diminution of stainable marrow iron in early pregnancy has been taken as the criterion of body iron deficiency to which other tests have been compared. The results suggest that the lower limit of normal for serum iron of $70 \mu \mathrm{g} . \%$, and for percentage saturation of 20 , in non-pregnant subjects, is equally applicable in pregnancy. Elevation of the unsaturated iron-binding capacity in pregnancy was not necessarily indicative of iron deficiency, confirming the observations of Verloop, Meeuwissen, and Blokhuis (1958).

Although the beneficial effect of routine prophylatic use of iron supplementation during pregnancy is well substantiated (Benstead and Theobald 1952; Fisher and Biggs, 1955; Edgar and Rice, 1956), in some populations, especially in the developing countries, this may not be practical due to cost and erratic attendance of patients at ante-natal clinics. In patients showing iron-deficiency anaemia in early pregnancy, energetic iron therapy is necessary. However, a proportion of patients without anaemia in early pregnancy will develop iron-deficiency anaemia by term, and it is in this group that iron supplementation is necessary. If it were possible to identify this group in early pregnancy, prophylactic measures could be directed towards these patients. The results of the present study suggest that this is possible. In non-anaemic patients in early pregnancy, the state of the iron stores is the most sensitive index of iron deficiency, and there is a significant correlation between iron stores and the subsequent development of anaemia. Routine bone marrow examination in early pregnancy is obviously not feasible. While normal saturation of transferrin in early pregnancy is a reasonable guarantee against the development of anaemia, it may be even more difficult to meas this in every patient, and probably just as expensive, as routine iron administration.

$\overrightarrow{\omega^{2}}$

Iron deficiency in pregnancy may be accompanied by folate deficiency. The results of the present sturely do not suggest that concomitant folate deficiencysin early pregnancy will render tests of iron deficießicy less valid. It must be borne in mind, however, that severe folate deficiency is unusual in early pregnancy and the morphological changes noted in the present patients labelled as folate deficient were mild. Furthermore, virtually all patients with folate definiency were iron deficient as well. Bainton and Fincreh (1964) found changes in serum iron, unsaturated ironbinding capacity, and percentage saturation consistent with the diagnosis of iron deficiency in patients with megaloblastic anaemia and no demonstrable iron in the marrow. Perhaps elevation of serum iron, percentage saturation of transferrin, and increase in marrow iron stores, as a result of folate deficieney, only occur with severe folate deficiency in presence of adequate iron stores.

We wish to thank the Director, South African Institige for Medical Research, for facilities to carry out this study; Dr. T. H. Bothwell for the serum iron and iron-bindiong capacity measurements; and Dr. P. Pannall for his he and Misses V. Brandt, P. Welch, and M. Divaris for technical assistance.

\section{REFERENCES}

Bainton, D. F., and Finch, C. A. (1964). Amer. J. Med., 37, 62 Benstead, N., and Theobald, G. W. (1952). Brit. med. J., 1, 407. Bothwell, T. H., and Finch, C. A. (1962). Iron Metabolism. Churcḥ̣̂! London.

- and Mallett, B. (1955). Biochem. J., 59, 599.

Chanarin, I., and Bennett, M. C. (1962). Brit. med. J., 1, 27. MacGibbon, B. M., O'Sullivan, W. J., and Mollin, D. L. (1958) Lancet, 2, 634.

Edgar, W., and Rice, H. M. (1956). Ibid, 1, 599.

Fisher, M., and Biggs, R. (1955). Brit. med. J., 1, 385.

Herbert, V. (1961). J. clin. Invest., 40, 81.

Rath, C. E., and Finch, C. A. (1948). J. Lab. clin. Med., 33, 81.

Toepfer, E. W., Zook, E. G., Orr, M. L., and Richardson, L. R. (19म्) Folic Acid Content of Foods (Agric. Handbook No. 29, UsS. Dept. Agric.) Washington.

Verloop, M. C., Meeuwissen, J. E. T., and Blokhuis, E. W. M. (19\$3). Brit. J. Haemat., 4, 70.

Waters, A. H., and Mollin, D. L. (1961). J. clin. Path., 14, 335. 